\title{
A IMPORTÂNCIA DA INTELIGÊNCIA ARTIFICIAL NOS TRIBUNAIS BRASILEIROS PARA O DIRECIONAMENTO DE POLÍTICAS PÚBLICAS AMBIENTAIS NA AMAZÔNIA
}

\author{
Ágatha Gonçalves Santana1 \\ Universidade da Amazônia \\ agathadcpc@yahoo.com.br \\ Carla Noura Teixeira ${ }^{2}$ \\ Universidade da Amazônia \\ carlanoura@gmail.com \\ João Valério de Moura Junior ${ }^{3}$ \\ Universidade da Amazônia \\ jvmoura@gmail.com
}

\begin{abstract}
Resumo
O presente trabalho versa sobre os reflexos ocorridos a partir da quarta revolução industrial dentro do Poder Judiciário brasileiro, essencialmente a partir do uso da inteligência artificial e suas possibilidades, pela utilização dos dados sensíveis extraídos pelos sistemas de algoritmos programados a partir das ações propostas e catalogadas nos Tribunais do país no âmbito das políticas ambientais. O problema foca quais impactos essa mudança pode apresentar e como se pode obter melhorias na comunicação e estruturação de dados sensíveis para o direcionamento pontual das políticas ambientais e desenvolvimento de um Estado sustentável. Objetiva-se demonstrar que o uso dessas novas tecnologias pode acelerar estudos e ter um maior índice de acurácia, obtendose economia de tempo e capital, bem como uma melhoria na práxis. A metodologia predominante trata de pesquisa teórica de natureza básica, com objetivos exploratórios de natureza qualitativa, dentro da análise de procedimento documental, utilizando-se predominantemente a lógica dedutiva quando da análise da viabilidade e impactos estruturais da inteligência artificial nas políticas ambientais a partir de dados envolvendo ações judiciais. Concluise pela observação de uma viabilidade de desenvolvimento de políticas públicas ambientais para a Amazônia a partir dos dados sensíveis obtidos através da análise das ações ajuizadas referentes à danos e impactos ambientais, selecionados através dos algoritmos programados sobre o sistema do Processo Judicial Eletrônico.
\end{abstract}

Palavras-chave: Tribunais brasileiros. Inteligência Artificial. Novas Tecnologias. Políticas Ambientais. Estado sustentável.

\footnotetext{
${ }^{1}$ Advogada, Graduada em Direito pela Universidade da Amazônia (2006), Mestre (2009) e Doutora em Direito pela Universidade Federal do Pará (2017). Professora titular de Teoria Geral do Processo e Direito Processual Civil da Universidade da Amazônia - UNAMA SER.

${ }^{2}$ Doutora em Direito do Estado pela Pontifícia Universidade Católica de São Paulo (2009) e Mestre em Direito das Relações Sociais pela Pontifícia Universidade Católica de São Paulo (2003). Especialista em Direito Processual (2000). Graduada em Direito pela Universidade Federal do Pará. Advogada.

${ }^{3}$ Juiz de Direito do Tribunal de Justiça do Estado do Pará. Pós-Graduado em Direito Público pela Faculdade Integrada do Recife, Pernambuco. Mestre em Direitos Fundamentais pela Universidade da Amazônia, Belém, Pará. Cursa MBA em Gestão e Bussines Law pela Fundação Getúlio Vargas (FGV).
} 


\title{
THE IMPORTANCE OF ARTIFICIAL INTELLIGENCE IN BRAZILIAN COURTS FOR THE DIRECTION OF PUBLIC ENVIRONMENTAL POLICIES IN THE AMAZON
}

\begin{abstract}
This work deals with the reflexes that occurred since the fourth industrial revolution within the Brazilian Judiciary, essentially from the use of artificial intelligence and its possibilities, through the use of sensitive data extracted by the systems of algorithms programmed from the proposed and cataloged actions in the country's Courts within the scope of environmental policies. The problem focuses on what impacts this change can have and how improvements can be made in communicating and structuring sensitive data for the timely direction of environmental policies and the development of a sustainable state. The objective is to demonstrate that the use of these new technologies can accelerate studies and have a greater accuracy index, obtaining savings in time and capital, as well as an improvement in praxis. The predominant methodology deals with theoretical research of a basic nature, with exploratory objectives of a qualitative nature, within the analysis of documentary procedure, predominantly using deductive logic when analyzing the viability and structural impacts of artificial intelligence on environmental policies based on data involving lawsuits. It concludes by observing a feasibility of developing public environmental policies for the Amazon based on the sensitive data obtained through the analysis of the lawsuits related to environmental damage and impacts, selected through the algorithms programmed on the Electronic Judicial Process system.
\end{abstract}

Keywords: Brazilian courts. Artificial intelligence. New technologies. Environmental Policies. Sustainable state. 


\section{INTRODUÇÃO}

O século XXI vem sendo marcado pela conhecida "quarta revolução industrial", objeto de estudo e implementação em setores de todo mundo, com a finalidade de criação de sistemas inteligentes para auxiliar o ser humano na nova era, onde as informações circulam em ritmo acelerado, bem como a realidade e fenômenos sociais transformam-se na velocidade das mudanças tecnológicas, diariamente renovadas.

Um novo modelo tecnológico de gestão de dados é instalado, chamado data-driven, formado a partir de um banco de dados conhecido como Big Data, com o uso de tecnologia apropriada para a captura desses dados, dentro de um uso exponencial de informações que circulam na rede mundial de computadores.

Essa nova era, marcada pelo uso maciço de tecnologia para a automação e troca de dados, como no caso da internet das coisas e da computação em nuvem, dos veículos autônomos, biotecnologia, nanotecnologia, computação quântica, dentre outros setores, acaba por repercutir diretamente nos conceitos jurídicos, como também sobre o conceito de políticas públicas, devendo-se, da mesma forma, informatizar, mapear e direcionar suas finalidades a partir da estruturação de seus dados. Isso porque todas essas mudanças ocasiona a viabilidade de dados a serem geridos em prol de um serviço público comprometido com os interesses estatais, devendo-se repensar tais institutos face a nova era, dirigida para um Estado sustentável.

Com efeito, os institutos tomaram novas proporções com a sua evolução, fazendo com que se possa visualizar uma amplitude maior do uso dessas tecnologias para não apenas utilizar na redução de demandas ou solução mais célere de conflitos, podendo culminar em algo maior, alcançando também a busca por ações a partir de assuntos selecionados, alcançando os direitos fundamentais, possibilitando realizar mapeamentos para a atuação de políticas públicas, como a pontuação dos problemas ambientais.

Assim, tem-se como problema principal deste trabalho a questão de, como o uso das novas tecnologias, através da programação dos algoritmos, impactam diretamente na coleta dos dados sensíveis a serem melhor analisados e direcionados para políticas pontuais.

O objetivo deste estudo, portanto, tem por foco principal, a partir dessa nova realidade, demonstrar a nova feição a ser estruturada a partir da óptica jurídica conjuntamente com a tecnológica, de modo a maximizar a persecução do bem comum.

Consequentemente, há de se discutir criticamente resultados hipotéticos, essencialmente no que possa incrementar a gestão dos dados adquiridos, bem como a destinação dos dados sensíveis na conformidade do direito pátrio, segundo a novíssima legislação da Lei de Proteção 
de Dados Pessoais - LGPD, no sentido de como direcioná-los, bem como o desenvolvimento de políticas públicas para a realização e efetividade dos direitos fundamentais, direcionados para o desenvolvimento sustentável da realidade regional.

A metodologia aplicada é de pesquisa básica de caráter teórico, com objetivos exploratórios de natureza qualitativa interpretativa, dentro da análise de procedimento documental, utilizando-se predominantemente a lógica dedutiva quando da análise da viabilidade e impactos estruturais da inteligência artificial no direito e políticas públicas ambientais.

Os critérios de inclusão abarcam o estudo do Big Data, da inteligência artificial, e da gestão de dados sobre o data-driven, bem como a estruturação de dados e as mudanças que ocorreram dentro do novo modelo aplicado aos Tribunais brasileiros, a partir da programação de sistemas algoritmos para triagem e demonstração de dados em análise quantitativa, essencialmente sobre a gestão ambiental em um modelo sustentável.

O trabalho é estruturado em três partes, a saber: a primeira, para situar a evolução e impactos da quarta revolução industrial sobre os Tribunais Brasileiros, e como a feição jurisdicional firmou-se em uma feição eminentemente política e balizadora de políticas públicas; a segunda relacionada com a viabilidade da gestão socioambiental a partir dos dados obtidos pela inteligência artificial aplicada aos Tribunais brasileiros e por fim, a ultima parte, dedicada para a análise dos impactos dessas tecnologias para o mapeamento e direcionamento de políticas públicas no âmbito amazônico.

\section{EVOLUÇÃO DO DIREITO NOS TRIBUNAIS BRASILEIROS NO CONTEXTO DA QUARTA REVOLUÇÃO INDUSTRIAL}

A máxima carneluttiana de que o Direito é reflexo da vida humana e um instrumento educativo, tal qual a matemática, necessário para a convivência dos indivíduos, utiliza a lógica para a melhor arte de pensar e melhorar a vida humana, através das invenções e descobertas e as reduções do risco de erro, dentro das realizações do que é possível em um determinado momento (CARNELUTTI, 1951, p. 202-206).

Com a Constituição da República do Brasil de 1988 - CRFB/88, as litigiosidades se tornaram mais complexas, envolvendo não apenas direitos patrimoniais e extrapatrimoniais, como também sociais e coletivos, como no caso da proteção ambiental, cada vez mais ameaçada pelos riscos escalonáveis emergentes em basicamente todos os setores que envolvam 


\section{ARTIGO}

INOVAÇÃo

tecnologia, essencialmente em um contexto que muitos denominaram de "virada tecnológica no direito" (NUNES; BAHIA; PEDRON, 2020, p. 18).

A Jurisdição não poderia mais ser vista meramente como poder, função e atividade direcionada para uma mera solução de conflitos. Silva (2008, p. 09-23) já prelecionava que a jurisdição já não mais havia de ser entendida como no conceito romano de "dizer o direito", mas sim como instituição produtora de direitos, conferindo, assim, um viés eminentemente político a este poder estatal, formando um contorno mais politizado. O viés político observado nas práticas dos tribunais, tanto em essência como em produção acabava sendo inquestionável. O processo se redesenha em uma processualidade, na interpretação de seus próprios princípios, em uma simbiose entre o público e o privado (GRINOVER, 2018, p.05).

A Processualidade ou sistema pluriprocessual (TARTUCE, 2018, p. 72) tomaria o lugar da Jurisdição clássica, de modo que se deva construir a partir dos conflitos existentes na sociedade, para se chegar ao procedimento mais adequado a atingir uma solução efetiva e justa, ao que Grinover (2018, p. 33), indicou como a necessidade de uma instrumentalidade metodológica.

Neste ínterim, foi debatido o que seria a entrada na era da quarta revolução industrial, termo utilizado para definir não como um conjunto de tecnologias emergentes em uma transição em direção a novos sistemas disruptivos das próprias relações humanas preexistentes, como redes sociais, trabalho, economia, dentre outros setores sociais (PERASSO, 2020).

Iniciou-se uma fusão simbiótica entre o mundo físico, digital e biológico, juntando-se tecnologias como a inteligência artificial, a internet das coisas, a biologia sintética e os sistemas ciberfísicos, que impactam não apenas a indústria, como o próprio modo de viver humano e no meio ambiente em que vive. Fundiu-se o uso da tecnologia com a velocidade, ao mesmo tempo em que se discute a preocupação pela segurança dos dados, que rapidamente foram visualizados como formas de ativos a serem negociados (MAGNUS, 2020).

Dentro desse contexto de mudanças, desde a década de 90, no Brasil, país de modernidade tardia, iniciou-se uma época de inserções sutis do uso da tecnologia, mas que, para a época, significavam verdadeiras revoluções. Inicialmente, inseriu-se o uso do computador como substituto da máquina de escrever e, durante muitos anos, foi visto meramente desta forma, como algo mais lúdico e cômodo do que lidar com uma máquina datilográfica.

A legislação, ao longo dos anos, acompanhou as mudanças globais. A Emenda Constitucional 45 de 2004 também inaugurou reformas em todo o Poder Judiciário, culminando em leis como a Lei Federal 11.419/2006 (BRASIL, 2006), que dispõe acerca da informatização do processo judicial. Criado por essa emenda, o Conselho Nacional de Justiça - CNJ, editou a 


\section{ARTIGO}

INOVAÇÃo

Portaria 12/2006 (CNJ, 2006), inaugurando o Banco de Soluções do Poder Judiciário, bem como, em 2009, estabeleceu as dez metas de nivelamento que deveriam ser alcançadas por todo o Poder Judiciário, estando entre elas, a informatização e gestão eletrônica de seus processos (CNJ, 2009). Ocorreram muito mais mudanças em seguida. A Emenda Constitucional 85, de 26 de fevereiro de 2015, alterou e adicionou dispositivos constitucionais para atualizar o tratamento das atividades de tecnologia e inovação, no sentido de incentivar a formulação de políticas que incentivem alianças estratégicas voltada para a geração de produtos, processos e serviços inovadores, bem como a transferência e difusão de tecnologia (PORTELA et al., 2019, p. 27).

O acesso ao Poder Judiciário passou a ser virtual, com disponibilidade ininterrupta, passando a integrar no cotidiano forense videoconferências e sustentações orais à distância. $\mathrm{O}$ Poder Judiciário, assim, não apenas modifica suas feições e desconstrói sua natureza tradicional, como também sua atuação, que passa a ser sobre um verdadeiro gerenciamento de dados. O debate, tão necessário no Direito, passou a tentar acompanhar o ritmo acelerado das mudanças, fazendo com que não apenas as decisões pudessem ser ainda mais diversificadas e dissonantes, necessitando de mecanismos de uniformização e monitoramento.

Nos dias de hoje, a capacidade de gerenciamento das demandas judiciais em um país de mais de 81 (oitenta e um) milhões de processos é condição indispensável para efetivar a duração razoável dos feitos como direito fundamental, como no caso do meio ambiente, essencial para uma vida digna do indivíduo e de toda uma sociedade. Fruto do acesso à justiça fortalecido pelas ondas renovatórias (CAPPELLETTI, 1988, p. 26), o poder estatal tem sofrido com a inviabilidade de oferecer resposta à altura dos jurisdicionados, embora os esforços e as melhorias sejam visíveis pela análise dos dados produzidos pelo CNJ (2020).

Nesse contexto, o mundo mudou em uma velocidade inimaginável, e o profissional do direito é forçado a se reinventar em tempos líquidos, não ocorrendo de modo diverso com o Poder Judiciário, corporificado na atuação dos Tribunais. O tempo flui de modo diverso, tendo viés dicotômico. Há o tempo real, no qual o profissional deve se debruçar em produzir, ao mesmo tempo em que deve seguir o tempo abstrato de programas de computador, que se utilizado de modo inadequado, torna a ferramenta de trabalho algo que pode até mesmo atrasar ou desumanizar o indivíduo. Não é essa a proposta da nova era tecnológica, que deve devolver a feição humana ao profissional do direito, passando a otimizar o tempo com cálculos e análises através da inteligência artificial, alcançando o desiderato de economizar tempo a ser direcionado para sua produção a qual não poderá a máquina substituir. 
Exemplo disso foi a criação de cortes totalmente em plataforma digital situada na rede mundial de computadores, como ocorreu no Estado de Utah, nos Estados Unidos, utilizando-se da Inteligência artificial, dirigido a julgamentos totalmente online sem a necessidade da presença de advogados, ao que diminuiu um desgastante procedimento aplicando-se a predição das alegações das partes e das decisões judiciais, de modo a melhorar e antecipar os acordos realizados (UTAH COURTS, 2020).

Pode-se perceber que o direito, mundialmente, está sofrendo uma grande disruptura, não sendo diversa a situação brasileira, pensada e aplicada a metodologia ágil (agile software development) como forma de gerenciamento de projetos. Toda essa mudança paradigmática formou não apenas um novo mercado no âmbito do empreendedorismo jurídico, como também formou novos parâmetros desenvolvidos dentro da própria jurisdição.

O progresso da inteligência artificial preditiva de interesses culturais para a sua utilização em vendas e outros setores foi uma consideração a ser posta no mundo do Direito (DRUMMOND, 2020, p. 07). Assim ocorreu com o desenvolvimento e uso da chamada jurimetria, termo cunhado pelo americano Lee Loevinger (WOLKART, 2020, p. 09), que significa literalmente a união do direito com a estatística, podendo-se mensurar fatos e conflitos, antecipando-os, podendo planejar condutas para advogados, legisladores e mesmo gestores públicos de maneira estratégicas.

Por outro lado, não é demais ressaltar que essa necessidade de aproximação não se restringe unicamente em relação à advocacia, devendo também e principalmente ser aplicada nos âmbitos da administração pública, não apenas como forma de melhoria de seus serviços prestados em favor do bem comum, mas também como forma de mapear problemas a serem sanados, e como forma de garantia da dignidade da pessoa humana, garantindo ao que costumou chamar de "sociedade 5.0", uma garantia de centralização das atuações tecnológicas sobre o ser humano (DRUMMOND, 2020, p. 13).

Isso porque profissionais do direito poderão ser direcionados ao foco do que suas funções de fato se propõem, não perdendo tempo com burocracias ou estado caótico de organização de informações desnecessariamente. Ao mesmo tempo, a organização das demandas, preconizada outrora pelo CNJ, e a sua consequente categorização, facilitaria ao que se cunhou como "gestão processual" e "gestão de processos" (COELHO, 2015). Em relação ao poder público, essa catalogação vai muito mais além, podendo utilizar os dados coletados como forma de mapeamento de atuação pontual de políticas públicas ou mesmo para utilização no sentido de otimizar os acordos judiciais. 
Desta forma, a atividade do magistrado, antes vista como atividade meramente administrativa, burocrática e reduzida à fidelidade da lei, ganhou legitimação própria e reconhecimento institucional, realçando sua relevância política (CABRAL, 2019, p. 14).

Silva (2008, p. 265), há mais de uma década previu esta mudança, salientando que o próprio conceito de Poder Jurisdicional já é um conceito moderno, tornando-se um serviço público comprometido com seus interesses, mudando sua finalidade e abrangência, concretizando a democratização, a constitucionalização e a necessidade efetiva dos direitos fundamentais (PORTO, 2012).

\section{GESTÃO SOCIO-AMBIENTAL E O USO DA INTELIGÊNCIA ARTIFICIAL NOS TRIBUNAIS BRASILEIROS}

A preocupação com a gestão ambiental já estava presente nos primórdios da história, desde o descarte de resíduos domiciliares em Roma antiga até as legislações do período colonial do Brasil para regular a extração de recursos naturais. Especificamente no Brasil, fora criado o Estatuto da Terra em 1964, o Código de Defesa Florestal em 1965 e a Lei de proteção à fauna em 1967. Na mesma década, foi criado o Instituto Brasileiro de Desenvolvimento Florestal (NASCIMENTO, 2012, p. 17-18).

Na década de 70, o Brasil, influenciado pela Conferência de Estocolmo, criou a Secretaria Especial do Meio Ambiente (SEMA), com o objetivo de estabelecer normas e padrões a serem cumpridos para a preservação do meio ambiente, sendo que em 1981 foi sancionada a Lei federal 6.938 que estabeleceu a política nacional do meio ambiente, seguida de estudos de impacto ambiental e resoluções do Conselho Nacional do Meio Ambiente - CONAMA, ocasião em que se iniciou o debate sobre o conceito de desenvolvimento sustentável para evitar o colapso ambiental a partir do impacto da primeira, segunda e terceira revoluções industriais (NASCIMENTO, 2012, p. 18-19).

O Relatório de Brundtland, elaborado pela Comissão Mundial sobre o Meio Ambiente e Desenvolvimento em 1987, dentre outras situações, requer para seu mister um planejamento em prol da formação de um sistema político que assegure a participação dos cidadãos no processo decisório; um sistema econômico capaz de gerar excedentes e know-how em bases confiáveis e constantes; um sistema social que solucione tensões causadas por um desenvolvimento não equilibrado; um sistema de produção que preserve a base ecológica no desenvolvimento; um sistema tecnológico que busque constantemente novas soluções; um sistema internacional que estimule padrões sustentáveis de comércio e financiamento; e 
finalmente um sistema administrativo flexível capaz de se autocorrigir (NASCIMENTO, 2012, p. 31).

Na década de 90, com a ocorrência do Eco Rio92, foram expedidos outros dois documentos: A Carta da terra e a Agenda 21, todas dirigidas com a finalidade de desenvolvimento sustentável em prol da qualidade ambiental, ocorrendo uma mudança de enfoque na gestão, pela otimização de todo o processo produtivo bem como a redução dos impactos ambientais, a partir do conceito de prevenção e a utilização de tecnologias limpas, baseada na responsabilidade solidária, posteriormente desenvolvendo-se em um contexto de gestão ambiental nas organizações e empresas (NASCIMENTO, 2012, p. 21-22).

Da necessidade de proteção dos direitos fundamentais, desenvolveu-se o que se denominou de socioambientalismo, passando a abarcar o meio ambiente, entendido como recursos naturais, e também o aspecto social, a proteção das comunidades que vivem neste mesmo meio ambiente, muito forte em relação ao Brasil, país de dimensões continentais, ocasionando inevitavelmente grandes particularidades e necessidades locais a serem analisadas.

Com o avanço da quarta revolução industrial, paralelo a esse contexto, houve a preocupação mundial em se estabelecer princípios ético-jurídicos para a proteção de dados pessoais, preocupação essa abraçada pelo Brasil quando da promulgação da Lei federal número 12.965/2014, conhecida como "Marco Civil da Internet", posteriormente complementada com a Lei federal 13.709/2018, também conhecida como Lei Geral da Proteção de Dados Pessoais - LGPD.

Tais leis ocupam-se, dentre outras coisas, em regulamentar ao que se denomina Big Data, termo que não descreve apenas a tecnologia apropriada para a captura dos dados disponibilizados na rede mundial de computadores, como também o crescimento, disponibilidade e uso exponencial das suas informações, sejam elas estruturadas ou não estruturadas (PAIVA, 2020. p. 163). Não obstante, devem integrar ao restante do ordenamento jurídico, de modo a preservar como um todo o fundamento constitucional da dignidade da pessoa humana.

Vive-se em um momento em que se observa o movimento denominado de data-driven, dentro do novo modelo de gestão de dados (COELHO, 2019, p. 181) que, no âmbito do Poder Judiciário Brasileiro, mais especificadamente no Superior Tribunal de Justiça - STJ, chegou, no ano de 2018, a utilizar um software capaz de identificar temas da área da saúde para a utilização em sede de Incidente de Resolução de Demandas Repetitivas - IRDR's, posteriormente adotado como um Núcleo de Monitoramento de Perfis de Demandas NUMOPEDE - em Tribunais Estaduais, como no caso do Estado do Pará (RIBEIRO, 2020). 
A automatização e uso dos metadados já é uma realidade, a qual necessita ser legitimada após um debate ético e jurídico, bem como após identificada as barreiras de obtenção desses mesmos dados e a formação de um grande acervo digital - no conhecido do Big Data - dentro dos tribunais brasileiros. Não obstante, o estudo deste acervo ou banco de dados, não poderá ser estruturado de modo simplista ou aleatório, devendo ter em foco o estudo dirigido, para a consecução dos mais amplos fins do direito, em sua harmonia e integridade. O conhecimento transdisciplinar nunca foi tão necessário na nova era, essencialmente no que tange ao conceito de sustentabilidade e necessidade de preservação ambiental para toda a sociedade.

Visando estudar o uso da inteligência artificial e sua viabilidade, demonstrada através do direito comparado em solo nacional, desde os tribunais superiores, vislumbra-se a possibilidade de elaboração de uma triagem por algoritmos, sistemas de dados programados para fornecer respostas conforme a base de dados disponíveis (VALENTINI, 2018, p. 42-43), mapeando demandas em sua natureza, os sujeitos envolvidos, relacionando-os aos direitos fundamentais, de modo que se possa criticar a realidade já existente e desenvolver estratégias de efetivação dos princípios socioambientais.

O próprio Conselho da Justiça Federal, por meio da Portaria CJF-POR-2017/00369, de 19 de setembro de 2017 (CNJ, 2017), instituiu o Centro Nacional e Local de Inteligência na Justiça Federal com a finalidade de aprimorar o sistema de gerenciamento de demandas em lote a partir de um banco de dados, fazendo cumprir, inclusive, o disposto no artigo 196, o caput e parágrafo primeiro do artigo 979 do Código de Processo Civil, Lei Federal n. 13.105/2015 (CPC, 2015).

Essa preocupação está de acordo com o macrodesafio do Poder Judiciário melhorar a infraestrutura e governança da Tecnologia da Informação e Comunicação, definida pelo CNJ (2013), realizando a própria busca do CPC/2015 da racionalidade, integridade e coerência entre as decisões judiciais. A partir dessas premissas, busca-se a aplicação da tecnologia com a capacidade macro de identificar demandas, por meio da análise das situações concretas vivenciadas, permitindo uma rápida interação entre os destinatários das informações colhidas para a construção de um banco de dados capaz de indicar, com precisão, as questões jurídicas envolvidas, como mais um indicador a ser ponderado quando dos estudos de impactos ambientais locais.

Isso porque, com o tratamento e processamento dessas informações, em nível micro, é possível identificar as classes e assuntos mais presentes em determinada unidade judiciária ou região e fortalecer a cooperação entre os juízes para a construção de respostas dentro de um modelo de justiça preocupado, além da integridade (DWORKIN, 1999), como também de um 
Poder Público mais direcionado, conhecedor das possibilidades pontuais das suas políticas públicas, evitando assim, desperdícios em tempos de "modernidade líquida" (BAUMAN, 2011, p. 14).

Essa ideia acaba por provocar a democratização dos dados obtidos e a socialização do conhecimento, acabando por demonstrar a situação socioambiental de modo mais aproximado da realidade, podendo direcionar de modo pontual políticas públicas de meio ambiente urbano ou rural a partir de tais informações. Ora, se tais programas alcançam resultados no âmbito privado, os quais utilizam dos dados para melhor atender clientes e promover uma melhor accountability, o instrumento parece ser hábil para uma utilização em uma escala maior em prol do bem comum, podendo pensar em sua utilização para o âmbito das políticas públicas.

\section{OS IMPACTOS DO USO DAS TECNOLOGIAS NOS TRIBUNAIS NO MAPEAMENTO E DIRECIONAMENTO DE POLÍTICAS PÚBLICAS AMBIENTAIS DA AMAZÔNIA}

De acordo com Bucci (2019, p. 793), uma definição provisória de políticas públicas estaria relacionada a uma metodologia de aplicação, uma abordagem de programas de ação governamental voltados à concretização de direitos, possuindo estreita relação com a realização dos direitos fundamentais previstos na CRFB/88. Isso porque uma das características do movimento de ampliação do conteúdo jurídico da dignidade humana é a multiplicação das demandas por direitos; demandas diversificadas e pulverizadas na titularidade de indivíduos e da sociedade, clamada pela necessidade de um quadro de planejamento estratégico, com a eleição prioritária de fins ou objetivos comuns e a escolha dos meios mais adequados à sua consecução.

Assim, seriam instrumentos de aglutinação de interesses em torno de objetivos comuns, que passam a estruturar uma coletividade de interesses, de planejamento, racionalização e participação de seus titulares. Seus elementos seriam a grande finalidade da ação governamental, as metas nas quais se desdobra, os meios alocados para a realização das metas e os processos de sua realização. Para isso, deve-se conhecer não apenas o direito enquanto conjunto de normas e valores éticos a serem alcançados dentro da sociedade, como também o perfil social e as particularidades ambientais a serem geridas. Todo um quadro de informações deve ser montado quando da discussão de uma política pública efetiva e pontual, o que pode ser auxiliado pelo monitoramento das demandas através das informações coletadas pelo Poder 
Judiciário, quando acionado para solucionar lesão ou ameaça a lesão de direitos socioambientais.

O uso dessas informações fortalece a comunicação entre os operadores do direito e a relação interinstitucional, pois o intercâmbio de informações, além de acompanhar e monitorar o andamento das demandas seriadas, a partir de relatórios desenvolvidos com vistas a entender as questões estruturais. O diálogo institucional entre os poderes e atuação policêntrica entre os atores envolvidos são mecanismos aptos a qualificar a prestação jurisdicional e de políticas públicas, nesse sentido, ampliando o que Geetz (2004, p. 251) denominou de uma necessária sensibilidade sobre cada saber local.

Portanto, é uma forma eficaz para o desenvolvimento de estratégias a partir do mapeamento de demandas relacionadas aos direitos fundamentais extraídas do acervo judiciário, a partir da determinação de critérios de seleção sobre os pontos de estrangulamento dentro dos direitos fundamentais relacionados ao meio ambiente e sustentabilidade, necessários a serem abordados e realizados.

É o caso do necessário mapeamento de demandas sobre direitos de povos indígenas e quilombolas e seus reflexos da política ambiental dentro do contexto da Amazônia brasileira e mesmo da Amazônia Legal, tendo impacto sobre o conhecimento tanto dos dados dentro dos Tribunais Brasileiros e até mesmo uma perspectiva de cooperação com a Corte Interamericana de Direitos Humanos.

Também é o caso de políticas ambientais urbanas, dentro do planejamento das cidades. Tanto o âmbito micro como macro podem ser observados a partir dos dados obtidos pela estruturação de algoritmos programados, fornecendo uma visão do que se deseja e como se deseja atuar.

Pode-se, dessa forma, realizar as bases do socioambientalismo enquanto resposta à exploração predatória dos recursos naturais, ao desmatamento amazônico, a degradação ambiental gerada pelos grandes latifundiários e criação de grandes rodovias, hidroelétricas, dentre outras ocasiões que ameaçam a sobrevivência dos povos tradicionais da Amazônia, tanto no aspecto físico como cultural.

O conhecimento pontual de um determinado local e de suas particularidades tem sido cada vez mais reconhecido na comunidade internacional como componente estratégico para o desenvolvimento de ações que resultem em um efetivo respeito à dignidade da pessoa humana, no sentido de conhecer e enfrentar problemas urbanos como degradação ambiental, problemas com saúde, cultura, educação, dentre outros temas demandados e judicializados. 
Com o conhecimento das demandas locais, diagnosticado a partir da estruturação organizada dos dados, através da utilização da Inteligência Artificial, pelo refinamento de busca em sistemas algoritmos ao aplicar as novas tecnologias, poder-se-ia mapear problemas e pensar em soluções de modo mais pontual, reduzindo impactos na economia estatal, no sentido de evitar tentativas puramente teóricas ou intuitivas, bem como maximizar a possibilidade de acerto para a população em relação à atuação do Poder Público sobre os princípios ambientais calcados no direito internacional e nacional.

\section{CONSIDERAÇÕES FINAIS}

A utilização da inteligência artificial para a estruturação de dados e a formação de um Big Data a partir dos processos ajuizados podem, indubitavelmente, serem fonte de insumos para que políticas públicas possam ser aplicadas de modo mais efetivo e, com isso, maior economia para o erário público.

Destaca-se a necessidade do desenvolvimento de metodologias tecnológicas, a partir da aplicação da inteligência artificial para identificação de lesões ou ameaça a direitos ambientais, com a finalidade de manter a integridade do ordenamento jurídico e a economia sobre as políticas públicas e os desenhos das estratégias sobre as particularidades de cada região do Brasil.

Há ainda a necessidade de desenvolvimento de padrão de critérios, ou seja, a definição dos padrões de seleção a ser criados em um sistema, a partir da programação dos algoritmos, e de modelos que identifiquem padrões sobre os assuntos das demandas que envolvam lesão ou ameaça a direitos socioambientais e, possibilitar o mapeamento para que possam ser analisadas em sua essência estrutural e funcional, as quais possam culminar em melhorias.

Destaque-se que tais critérios devam estar em consonância com a Lei Geral de Proteção de Dados Pessoais, para que essa gestão de dados seja dada na forma de governança ética, a qual se possa submeter a um compliance e transparência.

Conclui-se pela utilização da inteligência artificial para a detecção de judicialização de direitos fundamentais de caráter socioambiental com a finalidade de elaboração de políticas públicas pontuais na região amazônica, que possam, retirar os insumos e mapear a origem de déficits de efetividade de direitos, fenômenos coletivos ou outros alvos de políticas públicas, as quais poderão ser mais pontuais e eficazes quando do seu desenvolvimento e estratégias de ação, como no caso de desmatamentos, hidrelétricas e seus impactos nos povos locais. 
Para que a revolução 4.0 possa se coadunar com a chamada Sociedade 5.0, assim colocada como a nova feição reconstruída deste poder na pós modernidade da quarta revolução industrial, faz-se necessária a aproximação com disciplinas como a filosofia e a ética, bem como com as ciências da computação, essencialmente para desenvolver meios legais e éticos para fins de captura das informações necessárias e dos meios de obtenção das informações acerca das demandas, garantindo um meio ambiente saudável e autossustentável. Desta forma, por meio da composição das demandas, é possível fixar os critérios de seleção (triagem e avaliação), discutidos através de equipe multidisciplinar, garantindo a pluralidade de ideias, experiências e visões, garantindo não apenas o aspecto democrático como potencializando os alcances da pesquisa.

Colhidos os dados, devem ser interpretado, conforme a experiência do direito comparado, bem como as já aplicadas em solo nacional por tribunais superiores e estaduais, tanto doutrinárias como empíricas, sempre analisando as possibilidades de aplicação de Políticas Públicas pontuais aos casos encontrados para a solução de problemas, bem como as possibilidades de traçar metas para economia processual em relação às demandas que tramitam no Judiciário Brasileiro, de modo a efetivar as bases do sociambientalismo, bem como cooperar internacionalmente com as cortes internacionais.

Desta forma, é essencial o estudo de viabilidade e impacto do uso da inteligência artificial e o desenvolvimento de algoritmos dentro do Poder Judiciário, para que possa fornecer aos demais poderes e mesmo a sociedade como um todo as informações necessárias no sentido de maximizar os resultados e reduzir os custos a partir de estratégias pontuais sobre as demandas específicas, como ocorre na região amazônica, que rompe barreiras transnacionais. 


\section{REFERÊNCIAS}

BAUMAN, Z. Modernidade Líquida. Rio de Janeiro: Zahar, 2011, p. 14.

BRASIL. Conselho Nacional de Justiça. Justiça em Números 2018: ano-base 2017a.

Disponivel em:

http://www.cnj.jus.br/files/conteudo/arquivo/2018/09/8d9faee7812d35a58cee3d92d2df2f25.p

df. Acesso em: out. 2020.

BRASIL. Conselho Nacional de Justiça. Lei Federal 11.419 de 19 de dezembro de 2006. Brasília, 2006. Disponível em: http://www.planalto.gov.br/ccivil_03/_ato20042006/2006/lei/111419.htm Acesso em: nov. 2020.

BRASIL. Conselho Nacional de Justiça. PF combate esquema de fraudes de $\mathbf{R} \$ \mathbf{5}$ mi em benefícios previdenciário no Ceará. Agência PF (notícias antigas). 23 jun. 2016. Disponível em: http://www.pf.gov.br/agencia/noticias/2016/06/pf-combate-esquema-de-fraudes-de-r-5mi-em-beneficios-previdenciarios-no-ceara. Acesso em: nov. 2020.

BUCCI, Maria Paula Dallari. Método e aplicações da abordagem direito e políticas públicas (DPP). Revista Estudos Institucionais, Rio de Janeiro, v. 5, n. 3, p. 791-832, set./dez. 2019.

CABRAL, Trícia Navarro Xavier. Limites da liberdade processual. São Paulo: Foco, 2019.

CAPPELLETTI, M.; GARTH, B. Acesso à justiça. Porto Alegre: Sergio Antonio Fabris Editor, 1988,168 p. 26

CARNELUTTI, Francesco. Matematica e Diritto. In: CARNELUTTI, Francesco;

CALAMANDREI, Piero. Rivista di Diritto Processuale, Milano, Cendon Padova, v. 6. n. 1, 1951.

COELHO, Alexandre Zavaglia P. Jurídico data-driven: ciência de dados e design na área do direito. In: MALDONALDO, Viviane Nóbrega; FEIGELSON, Bruno (coords.). Advocacia 4.0. Revista dos Tribunais, São Paulo, 2019.

COELHO, Nuno. Gestão dos Tribunais e gestão processual. Lisboa: Centro de Estudos Judiciários, 2015.

CONSELHO NACIONAL DE JUSTIÇA. CNJ definirá as ações para o cumprimento dos macrodesafios. Brasília: Conselho Nacional de Justiça, 2013. Disponível em: https://www.cnj.jus.br/cnj-definira-as-acoes-para-o-cumprimento-dos-macrodesafios-2/ Acesso em: nov. 2020.

CONSELHO NACIONAL DE JUSTIÇA. Justiça em Números 2018: ano-base 2017. Brasília: Conselho Nacional de Justiça, 2017. Disponivel em: http://www.cnj.jus.br/files/conteudo/arquivo/2018/09/8d9faee7812d35a58cee3d92d2df2f25.p d. Acesso em: mar. 2020.

CONSELHO NACIONAL DE JUSTIÇA. Metas de nivelamento 2009. Belo Horizonte, 2009. Disponível em: https://www.cjf.jus.br/cjf/planejamento/metas-do-poderjudiciario/metas-de-nivelamento-2009 Acesso em: nov. 2020. 
CONSELHO NACIONAL DE JUSTIÇA. Portaria n. CJF-POR-2017/00369 de 19 de setembro de 2017. Dispõe sobre a instituição do Centro Nacional e Local de Inteligência da Justiça Federal e dá outras providências. Brasília: Conselho Nacional de Justiça, 2017. Disponível em: https://www.cjf.jus.br/observatorio/arq/CJF-POR-2017-00369.pdf. Acesso em: out. 2020.

DRUMMOND, Marcílio Henrique Guedes. Os paradigmas da Sociedade 5.0 no Direito. In: ALVES, Isabella Fonseca; DRUMMOND, Marcílio Guedes. Advocacia 5.0. Belo Horizonte: D’Plácido, 2020.

DWORKIN, R. O Império do Direito. 1. ed. São Paulo: Martins Fontes, 1999.

GEERTZ, Clifford. O saber local: Novos ensaios de antropologia interpretativa. 7 ed. Petrópolis: Vozes, 2004.

GRINOVER, Ada Pellegrini. Ensaio sobre a processualidade. 2 ed. Distrito Federal: Gazeta Jurídica, 2018.

MAGNUS, Tiago. Indústria 4.0: A quarta revolução industrial. Florianópolis: Tudo Digital, 2017. Disponível em; https://transformacaodigital.com/transformacao-digital/industria-4-0/ Acesso em; mar. 2020.

NASCIMENTO, Luis Felipe. Gestão ambiental e sustentabilidade. Brasília: UFSC, 2012. Disponível em:

https://www.ufjf.br/engsanitariaeambiental/files/2012/09/Livrotexto_Gestao_Ambiental_Sust entabilidade.pdf Acesso em: jan. 2021.

NUNES, Dierle; BAHIA, Alexandre; PEDRON; Flávio Quinaud. Teoria Geral do Processo: Com comentários sobre a virada tecnológica do direito processual. Salvador: Juspodvm, 2020.

PAIVA, Danúbia. A tutela dos dados pessoais na era do "Big Data". In: ALVES, Isabella Fonseca (org.). Inteligência artificial e processo. Belo Horizonte: D’Plácido, 2020.

PERASSO, Valéria. O que é a 4 revolução industrial e como ela pode afetar nossas vidas. News: BBC Brasil, 2016. Disponível em: https://www.bbc.com/portuguese/geral-37658309 Acesso em: mar. 2020.

PORTELA, Bruno Monteiro. et al. Marco Legal de Ciência, Tecnologia e Inovação no Brasil. Salvador: Juspodvm, 2019.

PORTO, Sérgio Gilberto. Processo civil contemporâneo: elementos, ideologia e perspectivas. Salvador: Juspodvm, 2018.

SILVA, Ovídio Araújo Baptista da. Jurisdição, direito material e processo. Rio de Janeiro: Forense, 2008, p. 265.

TARTUCE, Fernanda. Mediação nos conflitos civis. 4 ed. São Paulo: Método, 2018.

UTAH COURTS. Ocaps. Utah. 2020. Disponível em: https://www.utcourts.gov/ocap/ Acesso em: mar. 2020. 


\section{ARTIGO}

- INOVAÇÃo

VALENTINI, Romulo Soares. Julgamento por computadores? As novas possibilidades da juscibernética no século XXI e suas implicações para o future do direito e do trabalho dos juristas. Tese (Doutorado em Direito). Belo Horizonte - Universidade Federal de Minas Gerais, Faculdade de Direito, 2018.

WOLKART, Erik; BECKER, Daniel. Tecnologia e precedentes: do portão de Kafta ao Panóptico digital pelas mãos da jurimetria. In: ALVES, Isabella Fonseca (org.). Inteligência artificial e processo. Belo Horizonte: D’Plácido, 2020 